Check for updates

Cite this: J. Anal. At. Spectrom., 2022, 37,677

Received 2nd December 2021 Accepted 31st January 2022

DOI: 10.1039/d1ja00421b

rsc.li/jaas

\section{Parallel flow ablation cell for short signal duration in LA-ICP-TOFMS element imaging}

\author{
Christoph Neff, (D) Pascal Becker (iD) and Detlef Günther (iD *
}

The acquisition speed in laser ablation inductively coupled plasma mass spectrometry element imaging depends significantly on the laser aerosol transport system. The faster the aerosol washout, the faster the acquisition can be carried out. Here, we introduce a modified ablation cell based on the tube cell design for laser ablation inductively coupled plasma time-of-flight mass spectrometry (LA-ICP-TOFMS) element imaging which provides shorter signal durations. The parallel flow ablation cell (PFAC) included a recess in the cover for improved gas flow pattern at the ablation site and achieved signal durations of $0.25 \mathrm{~ms}$ (FW0.1M) for ${ }^{44} \mathrm{Ca}$ and $0.29 \mathrm{~ms}$ (FW0.1M) for ${ }^{238} \mathrm{U}$ on NIST SRM 610 using a laser ablation repetition rate of $100 \mathrm{~Hz}$. Shortest signal duration was achieved using an inner cell to sample surface distance (CSD) of $700 \mu \mathrm{m}$, which is several times larger compared to previous fast washout ablation cells published and shows high tolerance to variations in the CSD. A shift in arrival time from the ablation to TOFMS extraction was observed when comparing light to heavy ions. $\mathrm{A}_{2}$ collision and reaction cell was not able to correct for this shift and lead to extended signal durations, but still very short signals of approximately $0.4 \mathrm{~ms}$ (FW0.1M) were observed. The robustness of the washout in a wide range of CSD makes the PFAC a promising ablation cell for fast aerosol transport and quasi-simultaneous detection of ions using an ICP-TOFMS and element imaging using $a \geq 1000 \mathrm{~Hz}$ laser ablation rate while maintaining the possibility for pulse-to-pulse signal separation.

\section{Introduction}

The coupling of laser ablation and inductively coupled plasma mass spectrometry (LA-ICP-MS) has been introduced in 1985 (ref. 1) and is today one of the most sensitive and widespread techniques for the detection and quantification of major to trace elements in a wide variety of solid materials. ${ }^{2}$ Almost two decades ago, Kindness $e t ~ a l .{ }^{3}$ demonstrated the capabilities of LA-ICP-MS in element imaging, which regained a lot of attention within the last decade. The speed of acquisition for imaging applications depends on many parameters, including the acquisition capabilities of the ICP-MS. However, the ablation cell and aerosol transport system are crucial parts for fast and robust image acquisitions.

Early attempts of LA-ICP-MS multi-element imaging required long signal durations due to the sequential nature of quadrupole and sector field instruments, which resulted in the use of large volume ablation cells. ${ }^{3,4}$ As such, the additional information gained by a multi-element analysis came at a cost of acquisition speed and a decrease of the signal-to-noise ratio. The high aerosol dispersion limited the separation of individual laser pulses, reduced the speed of acquisition and/or spatial

Laboratory of Inorganic Chemistry, Department of Chemistry and Applied Biosciences, ETH Zürich, Vladimir-Prelog-Weg 1, 8093 Zürich, Switzerland. E-mail: detlef. guenther@sl.ethz.ch information. This has changed with the introduction of the ICP time-of-flight mass spectrometer (ICP-TOFMS), ${ }^{5,6}$ which increased the appeal of low dispersion ablation cells developed within the last decade. ${ }^{7,8}$ The ICP-TOFMS is well suited to detect short transient signals of single laser pulses and has been successfully applied for element imaging.9-16 ICP-TOFMS systems allow quasi-simultaneous multi-element detection and an acquisition rate of 21.7 to $76.8 \mathrm{kHz} .^{13,16-19}$ Sequential mass analyzers, as for example sector field or quadrupole mass analyzers, do not allow stoichiometric multi-element detection of the short signals delivered from fast washout ablation cells. $^{20,21}$ TOFMS mass analyzers continuously detect ions, independent of data acquisition. As the entire spectrum is measured continuously, the high abundance of plasma background ions ${ }^{40} \mathrm{Ar}^{+}$and ${ }^{40} \mathrm{Ar}_{2}^{+}$can cause saturation and deterioration of the detector. Therefore, these ions are normally suppressed by notch filters ${ }^{19,22-24}$ or by using a collision and reaction cell (CRC). ${ }^{14,25-28}$

Short signal durations were achieved by reducing the volume of the ablation cell, decreasing the length of the transfer tube to the ICP, establishing laminar gas flows to reduce the dispersion of the aerosol and reducing the amount of generated aerosols by using smaller spot sizes. ${ }^{29-32}$ The tube cell design by Wang et $a l^{33}$ set new standards in the design and performance of ablation cells. In brief, the tube cell is a two-volume ablation cell $^{34}$ where the sample is placed on a 3D stage within a larger 
chamber. The ablation process is contained within a smaller volume, which is in line with the aerosol transport tube towards the plasma. The sample is placed below the tube, leaving a short inner cell to sample surface distance (CSD). The larger chamber, containing the sample and 3D stage, is filled with helium. This enables the ablation to take place within a helium atmosphere to produce smaller aerosol particles, allowing more effective vaporization of the aerosol particles in the ICP and improving the aerosol transport. ${ }^{35-37}$ The argon carrier gas is added to the aerosol transport tube. The dual inlet system makes further addition of argon unnecessary and avoids additional turbulences and further dispersion of the aerosol.

The applicability of LA-ICP-MS element imaging significantly increased with the development of several fast washout ablation cells, such as the tube cell, the sniffer cell and the half-open cell, as they all achieved signal durations of $<10 \mathrm{~ms}$ (full width at $1 \%$ of the maximum, FW $0.01 \mathrm{M}) .^{10,32,38}$ This allowed working with laser repetition rates of $\geq 100 \mathrm{~Hz}$ with minimal pulse-to-pulse signal mixing. Due to the faster sampling it became possible to image larger areas or to improve the spatial resolution while maintaining reasonable measurement times., ${ }^{\mathbf{9 1 4}, \mathbf{3 1}}$ In addition, shorter signal durations increase the signal-to-noise ratio and improve the LOD. ${ }^{31}$

Tanner and Günther ${ }^{39}$ skipped the ablation cell and the aerosol transport tube by developing an in-torch ablation approach. This enabled a signal duration of single laser pulses of 1-3 ms and was considered a physical limit or at least a benchmark hard to overcome. Recently, Van Acker et al. ${ }^{\mathbf{4 0}}$ achieved even shorter signal durations of single laser pulses of $0.5 \mathrm{~ms}$ (FW0.1M) applying the cobalt ablation cell (Teledyne CETAC Technologies, USA) ${ }^{32,41}$ and the Aerosol Rapid Introduction System (ARIS, Teledyne CETAC Technologies, USA) ${ }^{\mathbf{3 2 , 4 2}}$ to transport the aerosol to the ICP-MS. In contrast to the tube cell, the cobalt ablation cell uses helium as ablation gas, helium as carrier gas and argon is added at a later stage outside the cell. Reducing the volume in the ablation area and of the aerosol transport tube, in combination with a straight aerosol transport tube to minimize turbulences, allowed the acquisition of such short signals.

In this paper, we present the parallel flow ablation cell (PFAC) and demonstrate the capabilities for short signal duration in LA-ICP-TOFMS for $\geq 1000 \mathrm{~Hz}$ element imaging. Therefore, the signal duration of single laser pulses was investigated on a glass reference material and on an organic polymer tuning material as used in geological and biological studies. In addition, the influence of a $\mathrm{H}_{2} \mathrm{CRC}$ on the signal duration was investigated.

\section{Experimental}

The PFAC is a modification of the tube cell design. ${ }^{33}$ It is a twovolume ablation cell incorporated in the same large volume cell as described by Gundlach-Graham et al. ${ }^{10}$ The tube size for the Ar delivery was reduced in height from a full tube to a half-tube. This lead to an enlarged opening for helium flowing into the ablation area compared to the tube cell as depicted in Fig. 1.

The PFAC was incorporated in an argon-fluoride (ArF) excimer LA system (193 nm, GeoLas C, Lambda Physik, Germany) and coupled to an ICP-TOFMS instrument (icpTOF2R, Tofwerk AG, Switzerland) where the vacuum pump was replaced by an UNO 065 D pump (Pfeiffer, Germany). The PFAC and the injector (Ø $2.5 \mathrm{~mm}, 483-20$, AHF analysentechnik AG, Germany) were connected via a straight tube with $3 \mathrm{~mm}$ inner diameter and a length of $36 \mathrm{~cm}$. The injector has an inlet of $5 \mathrm{~mm} \varnothing$ and tapers to an outlet of $2.5 \mathrm{~mm} \varnothing$. LA was carried out in a helium atmosphere $^{35}$ (99.999\%, PanGas AG, Switzerland) and argon gas (99.996\%, PanGas AG, Switzerland) served as the carrier gas. The piezo-electrically driven xyz translational stage $(1 \mathrm{~nm}$ scan resolution, SmarAct GmbH, Germany), the laser and the TOFMS data acquisition were triggered using the custom-built imaging control system. ${ }^{\mathbf{1 3}}$

The reference materials NIST SRM 610 and a 3-Element Full Coverage Tuning Slide (Fluidigm, USA) containing Y, Ce, and Lu in an organic polymer (polymethylmethacrylate) were used to evaluate the capabilities of the PFAC for short signal durations. ${ }^{\mathbf{4 3 4} 4}$ The LA-ICP-TOFMS system was tuned using NIST SRM 610 for high signal intensity, a $\mathrm{Th}^{+} / \mathrm{U}^{+}$ratio of approx. 1 , while keeping the oxide formation low. Within these boundaries, the ablation gas flow (He) and the carrier gas flow (Ar) were tuned for short signal duration of single laser pulses, leading to a $\mathrm{ThO}^{+} / \mathrm{Th}^{+}$ratio of approx. $1 \%$ and $\mathrm{P}^{2+} / \mathrm{Pr}^{+}$ratio of approx. $1 \%$. The operating conditions are given in Table 1 . The ratio of the ablation gas flow and the carrier gas flow were of major importance to acquire short signals. The data evaluation and the plots were made using an in-house written script running on R using the RStudio IDE. ${ }^{45,46}$

The data acquisition structure of the ICP-TOFMS was already discussed in the ESI of an earlier publication..$^{13}$ In brief, the ICP-

\section{a)}

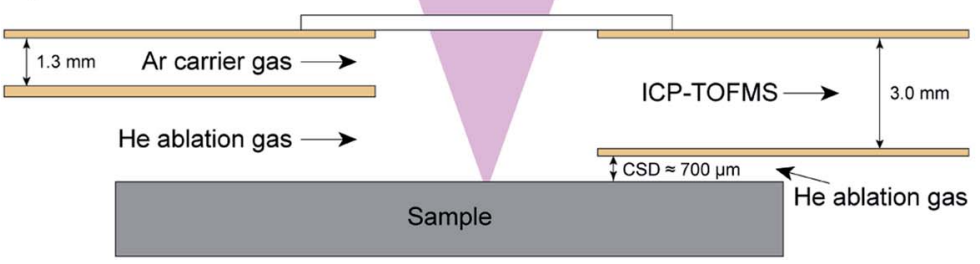

b)

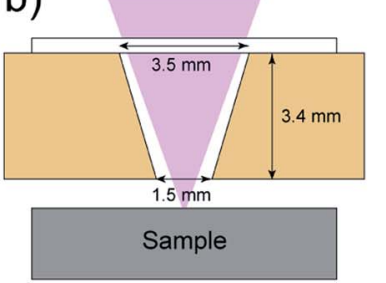

c)

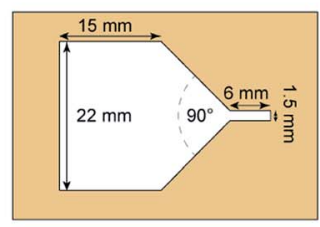

Fig. 1 Schematic drawing of the PFAC. (a) Vertical cross section along the transport tube to the ICP-TOFMS. (b) Cross section across the transport tube at the point of ablation. The trapezoid shape in the ablation area is converted to a circular transport tube to transport the aerosol to the ICP-TOFMS. (c) Horizontal cross section along the lower tube wall towards the ICP-TOFMS. The scale is different to (a) and (b). 
Table 1 LA-ICP-TOFMS operating parameter
Laser fluence

Laser repetition rate

Laser spot diameter

Sample moving speed

Cell to sample surface distance (CSD)

Carrier gas flow (Ar)

Auxiliary gas flow (Ar)

Plasma power
Ablation gas flow (He)

Cooling gas flow (Ar)

Notch filters
$15-20 \mathrm{~J} \mathrm{~cm}^{-2}$

$100 \mathrm{~Hz}$

$5 \mu \mathrm{m}$

$500 \mu \mathrm{m} \mathrm{s}^{-1}$

$700 \mu \mathrm{m}$

1.2-1.6 $\mathrm{L} \mathrm{min}^{-1}$

$0.7-0.8 \mathrm{~L} \mathrm{~min}^{-1}$

$0.8 \mathrm{~L} \mathrm{~min}^{-1}$

$16 \mathrm{~L} \mathrm{~min}^{-1}$

$1400 \mathrm{~W}$

${ }^{40} \mathrm{Ar}^{+},{ }^{40} \mathrm{Ar}_{2}{ }^{+},\left({ }^{23} \mathrm{Na}^{+}\right)$
TOFMS measures one full mass spectrum every $46 \mu$ s (1 waveform). This generates multiple GB $\mathrm{s}^{-1}$ of data. The USB 3.0 transfer rate between the TOFMS detector and the computer $\left(250 \mathrm{MB} \mathrm{s}^{-1}\right)$, the SSD writing speed $\left(200 \mathrm{MB} \mathrm{s}^{-1}\right)$ and the CPU load limit the data acquisition rate. For continuous data acquisition multiple TOFMS waveforms are averaged on the instrument site before sending to the computer. This allowed the highest possible continuous data acquisition rate at one full mass spectrum every $1.058 \mathrm{~ms}$ (average of 23 waveforms). This does not allow to study the signal structure of short laser signals with $<1 \mathrm{~ms}$ signal duration. Therefore, a triggered data acquisition approach was used to apply the full acquisition speed of the TOFMS instrument.

With each laser pulse a TOFMS measurement was triggered for the acquisition of 50 spectra (50 segments) with 1 waveform each leading to a total acquisition time of $2.3 \mathrm{~ms}$. This allowed for a high speed acquisition of 20 laser pulses stored in 20 bufs. Altogether they were combined in 1 write and saved to make the data accessible. A second write could not be saved. Therefore, for each measurement 20 laser pulses were acquired with $100 \mathrm{~Hz}$ laser repetition rate in highest time resolution.

\section{Results and discussion}

During previous LA-ICP-TOFMS imaging studies using the tube cell $^{\mathbf{1 0}}$ we noticed reproducible shorter signal duration while ablating at the samples edge pointing away from the plasma. This inspired the redesign of the cell. We rationalized a modified and improved ablation cell which should mimic the mentioned effect of edge ablation and enable an accented $\mathrm{He}$ gas flow to push the aerosol in the direction of the plasma. This was implemented in the PFAC by an enlarged opening for helium flowing into the cell (Fig. 1).

The first few laser pulses in each line scan on NIST SRM 610 lead to higher signal duration compared to the subsequent laser pulses (Fig. 2). This could be explained by a higher laser output energy during the first few laser pulses or by a positive effect of consecutive laser pulses for a stable aerosol transport. Nonetheless, all signals for all the laser pulses and all elements were $<0.8 \mathrm{~ms}$ (FW0.1M). This phenomenon does not interfere with the imaging acquisition at $1000 \mathrm{~Hz}$, but it means that imaging at $>1000 \mathrm{~Hz}$ should always start outside the area of interest to maintain the short washout time on the imaged area. On the other hand, these measurements also revealed single laser

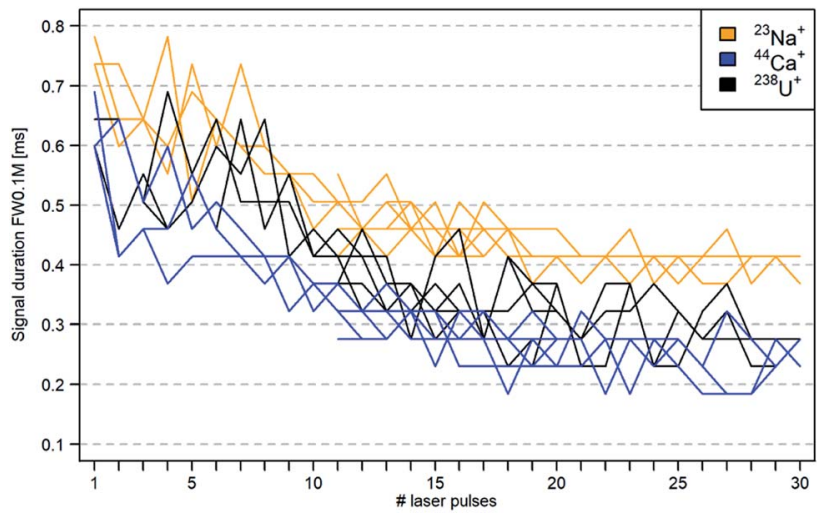

Fig. 2 The signal duration of each laser pulse on NIST SRM 610 is displayed according to the laser pulse number in the line scan. Three measurements of laser pulses 1 to 20 and three measurements of the laser pulses 11 to 30 are shown. The signal duration decreased significantly after 8-10 laser pulses.

pulses with signal durations of $<0.2 \mathrm{~ms}$ (FW0.1M) for ${ }^{44} \mathrm{Ca}$ are possible.

Therefore, for all the following measurements the laser pulses 11 to 30 in a line scan were acquired. With these settings, the PFAC achieved a signal duration of $0.25 \pm 0.03 \mathrm{~ms}$ (FW0.1M) for ${ }^{44} \mathrm{Ca}$ and $0.29 \pm 0.05 \mathrm{~ms}$ (FW0.1M) for ${ }^{238} \mathrm{U}$ for NIST SRM 610 . The signal duration is based on the average of the individual signal durations of 20 laser pulses and their respective standard deviation. An extensive list of the achieved signal durations for other elements are given in Table 2. The PFAC achieved a signal duration of $<0.3 \mathrm{~ms}$ (FW0.1M) for most of the elements. With one exception, no significant difference between major and minor elements was observed. The signal duration of ${ }^{23} \mathrm{Na}$ was distinctly larger (approx. 0.4 ms FW0.1M) compared to all the other elements for every experiment. An explanation could be that the low ionization potential and the low mass of $\mathrm{Na}$ lead to a further spread of $\mathrm{Na}$ ions in the plasma plume during ablation. ${ }^{47}$ Another reason could be the early

Table 2 Average signal duration of 20 laser pulses with respective standard deviation of isotopes across the mass spectrum. The standard deviation of $30-50 \mu$ is close to the acquisition time of one waveform (46 $\mu$ s). Therefore, the standard deviation could be substantially biased by the discrete data acquisition

\begin{tabular}{lll}
\hline Isotope & $\begin{array}{l}\text { Signal duration } \\
\text { (FW0.1M) }\end{array}$ & Standard deviation \\
\hline${ }^{23} \mathrm{Na}$ & $0.36 \mathrm{~ms}$ & $0.04 \mathrm{~ms}$ \\
${ }^{27} \mathrm{Al}$ & $0.26 \mathrm{~ms}$ & $0.05 \mathrm{~ms}$ \\
${ }^{29} \mathrm{Si}$ & $0.27 \mathrm{~ms}$ & $0.03 \mathrm{~ms}$ \\
${ }^{44} \mathrm{Ca}$ & $0.25 \mathrm{~ms}$ & $0.03 \mathrm{~ms}$ \\
${ }^{59} \mathrm{Co}$ & $0.27 \mathrm{~ms}$ & $0.04 \mathrm{~ms}$ \\
${ }^{89} \mathrm{Y}$ & $0.26 \mathrm{~ms}$ & $0.05 \mathrm{~ms}$ \\
${ }^{115} \mathrm{In}$ & $0.34 \mathrm{~ms}$ & $0.04 \mathrm{~ms}$ \\
${ }^{133} \mathrm{Cs}$ & $0.29 \mathrm{~ms}$ & $0.03 \mathrm{~ms}$ \\
${ }^{159} \mathrm{~Tb}$ & $0.28 \mathrm{~ms}$ & $0.03 \mathrm{~ms}$ \\
${ }^{232} \mathrm{Th}$ & $0.27 \mathrm{~ms}$ & $0.05 \mathrm{~ms}$ \\
${ }^{238} \mathrm{U}$ & $0.29 \mathrm{~ms}$ & $0.05 \mathrm{~ms}$
\end{tabular}



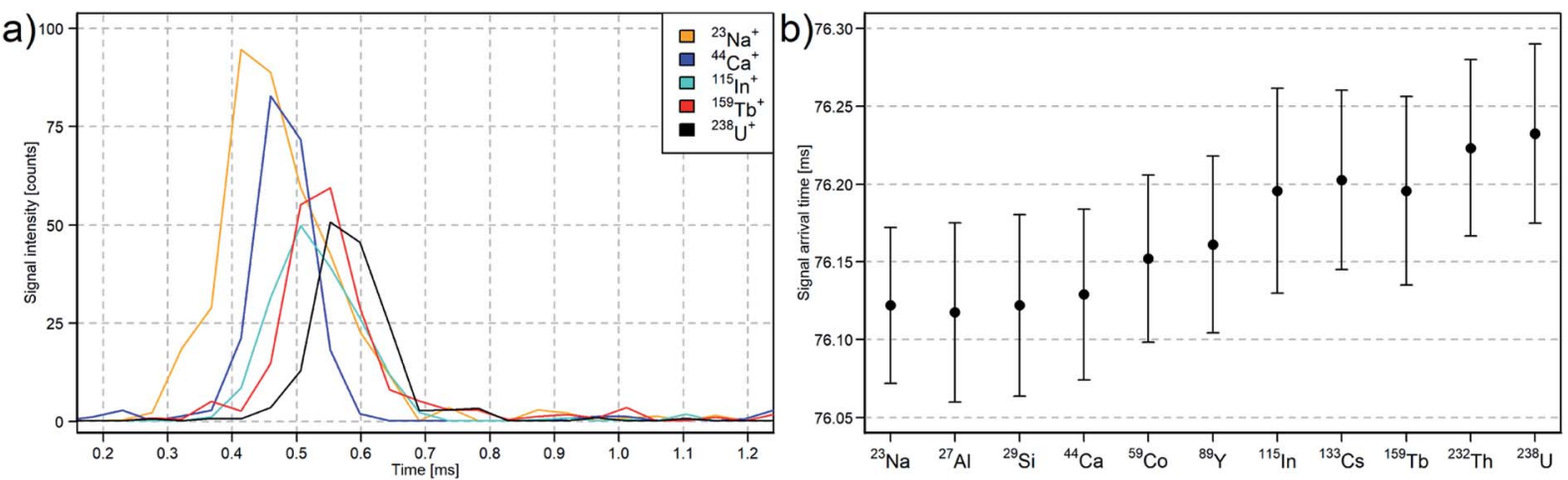

Fig. 3 (a) Triggered ICP-TOFMS signal of one laser pulse. Short signal durations are acquired for all elements. The peak maximum shifts from low to high $\mathrm{m} / \mathrm{z}$. (b) Peak maximum signal arrival time after triggering of the laser and the TOFMS data acquisition of selected elements across the mass spectrum. The error bars represent the standard deviation of the arrival time.

ionization of $\mathrm{Na}$ and the diffusion in the ICP due to space charge effects. Other low mass elements could also be affected but the signal intensity was not sufficiently high for measuring the signal duration.

The detection of short single laser pulses at high time resolution revealed mass dependent ion arrival at the TOFMS (Fig. 3). Lighter ions reached the TOFMS earlier compared to heavier ions. The average of the arrival time of the peak maximum for ${ }^{238} \mathrm{U}$ was delayed by $110 \pm 30 \mu$ s compared to ${ }^{23} \mathrm{Na}$. This is in good agreement with the mass dependent ion arrival at the TOFMS reported for microdroplet sample introduction and is caused by different travelling speeds after the extraction from the plasma. ${ }^{28,48}$

The signal maxima of the ${ }^{238} \mathrm{U}$ ions were detected $76.2 \mathrm{~ms}$ after the trigger signals were sent simultaneously to the laser and to the TOFMS data acquisition. Therefore, each trigger signal for the TOFMS data acquisition from the imaging control system was delayed by $75.6 \mathrm{~ms}$ to acquire the transient signals within the acquired time period of $2.3 \mathrm{~ms}$. The arrival time varied within $60 \mu \mathrm{s}(1 \sigma)$, which is comparable to Van Malderen et al. ${ }^{49}$ applying the cobalt ablation cell in combination with the ARIS. The overlap of the triggered signals of 20 laser pulses illustrates the variation in arrival time, which is assumed to be predominantly induced by the aerosol transport to the ICP (Fig. 4a). The mass dependent ion arrival at the TOFMS on the other hand is most likely induced by the ion optics of the ICPTOFMS. ${ }^{28,48}$

The analysis of the organic polymer tuning slide was performed using a laser fluence of approx. $1 \mathrm{~J} \mathrm{~cm}^{-2}$ and lead to signal durations of $0.39 \pm 0.04 \mathrm{~ms}, 0.41 \pm 0.04 \mathrm{~ms}$, and $0.43 \pm$ $0.04 \mathrm{~ms}$ (FW0.1M) for ${ }^{89} \mathrm{Y},{ }^{140} \mathrm{Ce}$, and ${ }^{175} \mathrm{Lu}$, respectively (Fig. 4b). The signal duration is slightly larger compared to NIST SRM 610. This sample dependent signal duration might be caused by the formation of gaseous $\mathrm{CO}_{2}$ during the ablation and aerosol formation and is leading to a further spread of the initial aerosol plume. ${ }^{40,50}$

The CSD is a crucial parameter for every two-volume ablation cell and was reported for other ablation cell designs to be optimal at 100-275 $\mu \mathrm{m} .{ }^{10,38,49}$ Smaller CSDs are challenging for the practicality of measurements ${ }^{38}$ and short signal durations were achieved in a limited narrow CSD range. ${ }^{49}$ The PFAC achieved shortest signal durations in the range of $650-800 \mu \mathrm{m}$ with optimum performance at $700 \mu \mathrm{m}$ (Fig. 5). At a CSD of $\leq 600 \mu \mathrm{m}$ the aerosol delivery became irregular and the signal duration increased. At CSD $>800 \mu \mathrm{m}$ the laser beam is larger than the cell entry width of $3.5 \mathrm{~mm}$ (Fig. 1). The larger CSD and larger
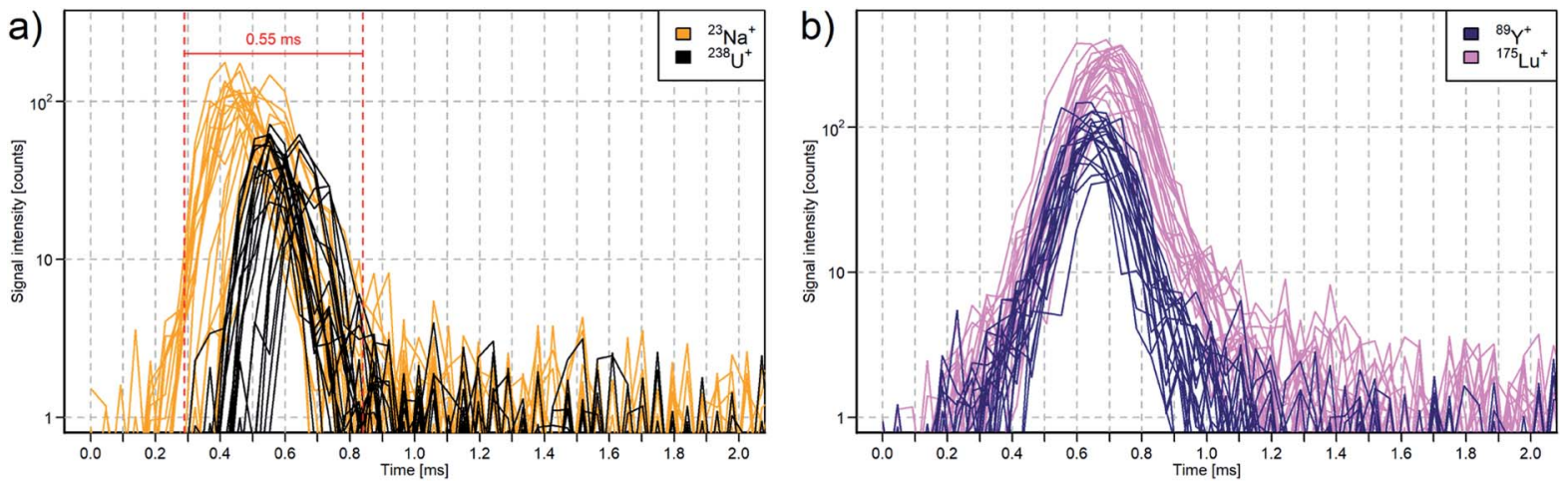

Fig. 4 Transient signals of 20 laser pulses on (a) the glass reference material NIST SRM 610 and (b) the 3-Element Full Coverage Tuning Slide containing $\mathrm{Y}, \mathrm{Ce}$, and $\mathrm{Lu}$. The shift in arrival time within the same element is mainly based on the aerosol transport, whereas the shift in arrival time between light and heavy ions is mainly based on the ion transport in the ion optics of the ICP-TOFMS. 


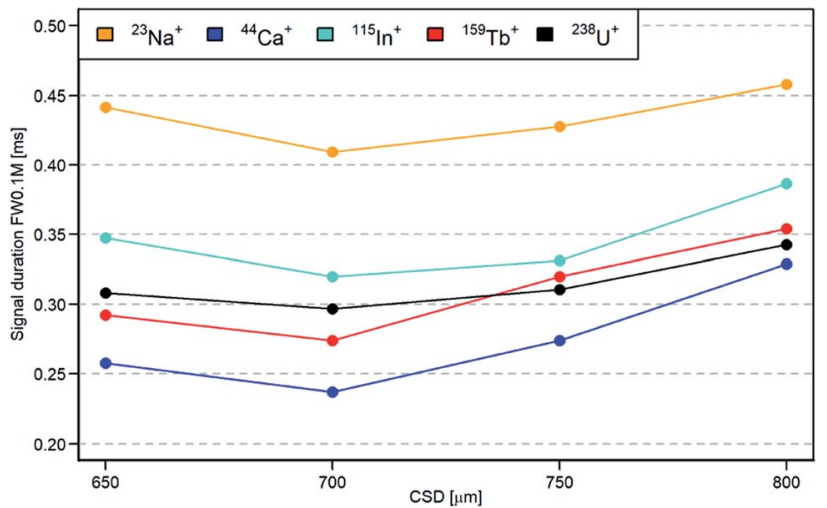

Fig. 5 Signal duration based on the CSD for elements across the mass spectrum.

useable range of CSD for short signal durations compared to other fast washout ablation cells reduced operational challenges. For example, accidental contact between the sample and the PFAC is less probable. The signal duration is less sensitive to different heights, which makes sample placement less critical. In addition, uneven samples such as glass fragments in forensic analysis can be analyzed..$^{51}$

\section{Collision and reaction cell}

Up to this point, all measurements of this study utilized the notch filters to prevent the detector from saturation with the background species ${ }^{40} \mathrm{Ar}^{+}$and ${ }^{40} \mathrm{Ar}_{2}{ }^{+}$. Applying a CRC with 2 $\mathrm{mL} \min ^{-1} \mathrm{H}_{2}$ allows the removal of the notch filters without saturating the detector with background species. ${ }^{51}$ Burger et al. ${ }^{28}$ reported that collisional cooling by a CRC running with He reduced the mass dependent ion arrival at the TOFMS for microdroplet sample introduction.

Therefore, a CRC with 2, 4, and $6 \mathrm{~mL} \min ^{-1} \mathrm{H}_{2}$ was applied in combination with the PFAC. The signal duration increased slightly when $\mathrm{H}_{2}$ was added to the CRC (Fig. 6a). The signal duration of Si increased significantly more with higher $\mathrm{H}_{2}$ gas flow compared to the other elements. The signal arrival time from ablation to the detection increases slightly for all elements (Fig. 6b). The peak maxima of the elements did not overlap. The arrival time of Si was observed to shift significantly more by approx. $600 \mu \mathrm{s}$ from $0 \mathrm{~mL} \mathrm{~min}{ }^{-1} \mathrm{H}_{2}$ to $6 \mathrm{~mL} \min ^{-1} \mathrm{H}_{2}$ when compared to the other elements which shifted by approx. 200 $\mu \mathrm{s}$. This behavior of Si can currently not be explained and was not further investigated in this study. The pixel signal intensity and the sensitivity can be improved by applying the CRC (Fig. 6c)..$^{28}$ Lighter isotopes such as ${ }^{23} \mathrm{Na}$ reached highest signal intensity at $0 \mathrm{~mL} \mathrm{~min}^{-1} \mathrm{H}_{2}$, whereas heavy isotopes such as ${ }^{238} \mathrm{U}$ reached highest signal intensity at $4 \mathrm{~mL} \min ^{-1} \mathrm{H}_{2}$. The change in signal intensity is mass dependent. A CRC with $2 \mathrm{~mL} \mathrm{~min}^{-1}$ $\mathrm{H}_{2}$ allowed the removal of the notch filters for the background species ${ }^{40} \mathrm{Ar}^{+}$and ${ }^{40} \mathrm{Ar}_{2}^{+}$and no additional notch filter for hydride species (e.g. $\left.{ }^{40} \mathrm{Ar}^{1} \mathrm{H}^{+}\right)$had to be applied. The element signal durations increased to approx. $0.4 \mathrm{~ms}(\mathrm{FW} 0.1 \mathrm{M})$ but were still very short. The peak maxima of all elements were detected within approx. $100 \mu \mathrm{s}$. In addition, the signal intensity for medium to heavy elements increased.

This study of the PFAC was limited by the maximal laser repetition rate of $100 \mathrm{~Hz}$ of the available laser system. Therefore, a final proof of the applicability of the PFAC for element imaging with $\geq 1000 \mathrm{~Hz}$ laser ablation rate while maintaining pulse-to-pulse signal separation cannot yet be experimentally provided. However, the PFAC achieved shortest ICP-MS signal durations reported so far. As already mentioned by Van Acker et al., ${ }^{40}$ nowadays ablation cells are approaching or already exceeding the currently used benchmark of the signal duration of a single nanoparticle.

For the application in LA-ICP-TOFMS element imaging not only the mere signal duration $(0.25-0.36 \mathrm{~ms})$ but also the combination of variation of the aerosol arrival time $(2 \sigma \approx 0.2$ $\mathrm{ms}$ ) and mass dependent shift of light and heavy element detection $(\approx 0.1 \mathrm{~ms})$ led to total signal duration of approx. 0.55 ms (Fig. 4a) as these three parameter are not fully independent from each other.

The signal duration depends on the aerosol formation, the transport speed and the ion cloud size. Therefore, a higher transport speed induced for example by higher gas flows could be beneficial, if the excitation conditions in the plasma are maintained. On the other hand, a smaller aerosol plume based on lower dispersion by smaller ablation cell volume or smaller aerosol transport volume as for example for the ARIS system could reduce the variation of aerosol arrival in the plasma and shorten the signal duration of the PFAC even further. A shorter
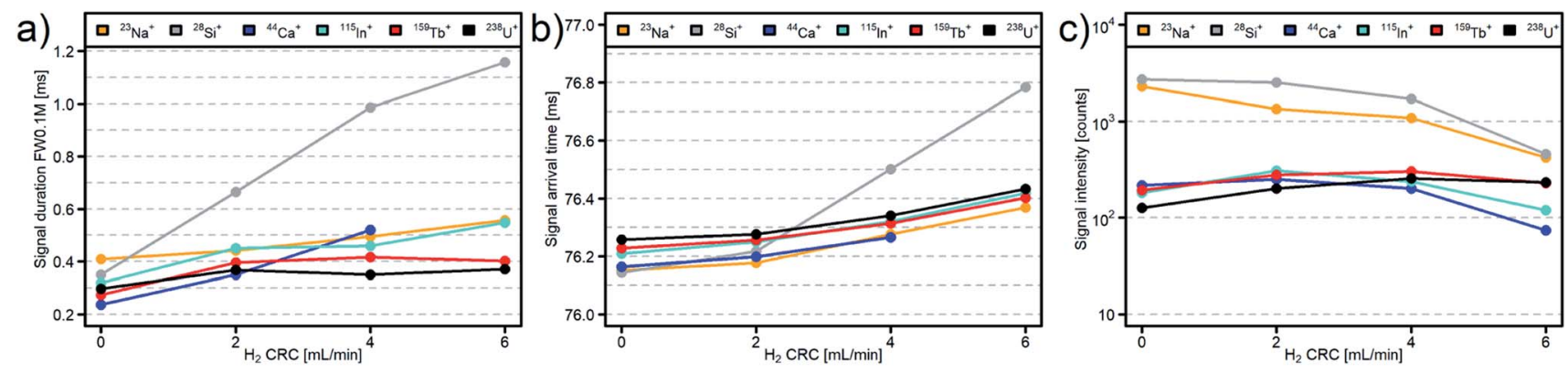

Fig. 6 Comparison of (a) the signal duration, (b) the peak maximum signal arrival time, and (c) the sum signal intensity of a laser pulse based on the $\mathrm{H}_{2}$ gas flow in the $\mathrm{CRC}$. 
distance in the ICP-TOFMS between the ion extraction from the plasma and the TOFMS extraction could also reduce the mass dependent shift of light and heavy isotopes.

For a long time, fast washout ablation cells were the limiting part for high speed element imaging. The bottleneck shifted to the access to lasers with repetition rates $\geq 1000 \mathrm{~Hz}$ and the limited speed of data acquisition with already fast TOFMS detection. The data acquisition could be accelerated by a faster data transfer, by reducing the amount of data in accordance with CyTOF technology ${ }^{\mathbf{1 8}}$ where only the signal intensities of selected mass windows instead of the full mass spectrum are saved or by reducing the number of data points when recording a full mass spectrum.

\section{Conclusion}

In this study we present a fast washout ablation cell for LA-ICPTOFMS imaging. Hitherto, the PFAC achieved shortest signal durations reported for LA sample introduction. It was already applied for LA-ICP-TOFMS element imaging ${ }^{\mathbf{1 3 , 1 4}}$ and shows a considerable increase in robustness compared to the tube cell. The applicability at a laser ablation sampling frequency of $\geq 1000 \mathrm{~Hz}$ would allow to acquire a 1 megapixel image within $<20 \mathrm{~min}$ and increase the sample throughput dramatically. In addition, costs to run the ICP-MS could be reduced. The application of a $\mathrm{H}_{2}$ CRC increased the signal duration slightly but would still allow imaging at a laser ablation sampling frequency above $1000 \mathrm{~Hz}$. Besides that, especially medium to heavy elements benefit from higher sensitivity. Therefore, the PFAC is a promising ablation cell for speeding up and expand the practically achievable image size for LA-ICP-TOFMS element imaging.

\section{Conflicts of interest}

There are no conflicts to declare.

\section{Acknowledgements}

The authors acknowledge the support from Gunnar Schwarz for comments on the manuscript and Roland Mäder of the ETH workshop for construction of the PFAC.

\section{References}

1 A. L. Gray, Analyst, 1985, 110, 551-556.

2 D. Günther and B. Hattendorf, TrAC, Trends Anal. Chem., 2005, 24, 255-265.

3 A. Kindness, C. N. Sekaran and J. r. Feldmann, Clin. Chem., 2003, 49, 1916-1923.

4 H. A. O. Wang, D. Grolimund, L. R. Van Loon, K. Barmettler, C. N. Borca, B. Aeschlimann and D. Günther, Anal. Chem., 2011, 83, 6259-6266.

5 D. P. Myers and G. M. Hieftje, Microchem. J., 1993, 48, 259277.

6 P. P. Mahoney, G. Li and G. M. Hieftje, J. Anal. At. Spectrom., 1996, 11, 401-405.
7 S. J. M. Van Malderen, A. J. Managh, B. L. Sharp and F. Vanhaecke, J. Anal. At. Spectrom., 2016, 31, 423-439.

8 A. Gundlach-Graham and D. Günther, Anal. Bioanal. Chem., 2016, 408, 2687-2695.

9 C. Giesen, H. A. O. Wang, D. Schapiro, N. Zivanovic, A. Jacobs, B. Hattendorf, P. J. Schüffler, D. Grolimund, J. M. Buhmann, S. Brandt, Z. Varga, P. J. Wild, D. Günther and B. Bodenmiller, Nat. Methods, 2014, 11, 417.

10 A. Gundlach-Graham, M. Burger, S. Allner, G. Schwarz, H. A. O. Wang, L. Gyr, D. Grolimund, B. Hattendorf and D. Günther, Anal. Chem., 2015, 87, 8250-8258.

11 A. Gundlach-Graham, P. S. Garofalo, G. Schwarz, D. Redi and D. Günther, Geostand. Geoanal. Res., 2018, 42, 559-574.

12 O. B. Bauer, O. Hachmöller, O. Borovinskaya, M. Sperling, H.-J. Schurek, G. Ciarimboli and U. Karst, J. Anal. At. Spectrom., 2019, 34, 694-701.

13 C. Neff, P. Keresztes Schmidt, P. S. Garofalo, G. Schwarz and D. Günther, J. Anal. At. Spectrom., 2020, 35, 2255-2266.

14 D. Rubatto, M. Burger, P. Lanari, B. Hattendorf, G. Schwarz, C. Neff, P. Keresztes Schmidt, J. Hermann, A. Vho and D. Günther, Contrib. Mineral. Petrol., 2020, 175, 61.

15 S. Theiner, A. Schweikert, C. Haberler, A. Peyrl and G. Koellensperger, Metallomics, 2020, 12, 1246-1252.

16 C. J. Greenhalgh, O. M. Voloaca, P. Shaw, A. Donard, L. M. Cole, M. R. Clench, A. J. Managh and S. L. HaywoodSmall, J. Anal. At. Spectrom., 2020, 35, 2231-2238.

17 D. T. Scott, R. B. Dmitry, O. Ornatsky, I. B. Vladimir, M. Nitz and M. A. Winnik, Pure Appl. Chem., 2008, 80, 2627-2641.

18 D. R. Bandura, V. I. Baranov, O. I. Ornatsky, A. Antonov, R. Kinach, X. Lou, S. Pavlov, S. Vorobiev, J. E. Dick and S. D. Tanner, Anal. Chem., 2009, 81, 6813-6822.

19 O. Borovinskaya, B. Hattendorf, M. Tanner, S. Gschwind and D. Gunther, J. Anal. At. Spectrom., 2013, 28, 226-233.

20 J. T. van Elteren, V. S. Šelih, M. Šala, S. J. M. Van Malderen and F. Vanhaecke, Anal. Chem., 2018, 90, 2896-2901.

21 B. Hattendorf, U. Hartfelder and D. Günther, Anal. Bioanal. Chem., 2019, 411, 591-602.

22 C. A. Flory, S. C. Hansen and C. Myerholtz, US Pat., 5672870, 1997.

23 M. Burger, A. Gundlach-Graham, S. Allner, G. Schwarz, H. A. Wang, L. Gyr, S. Burgener, B. Hattendorf, D. Grolimund and D. Gunther, Anal. Chem., 2015, 87, 8259-8267.

24 L. Hendriks, A. Gundlach-Graham, B. Hattendorf and D. Günther, J. Anal. At. Spectrom., 2017, 32, 548-561.

25 B. Hattendorf and D. Günther, J. Anal. At. Spectrom., 2000, 15, 1125-1131.

26 D. Günther, B. Hattendorf and A. Audétat, J. Anal. At. Spectrom., 2001, 16, 1085-1090.

27 P. R. D. Mason and W. J. Kraan, J. Anal. At. Spectrom., 2002, 17, 858-867.

28 M. Burger, L. Hendriks, J. Kaeslin, A. Gundlach-Graham, B. Hattendorf and D. Günther, J. Anal. At. Spectrom., 2019, 34, 135-146.

29 D. Günther and M. Gäckle, $P h D$ thesis, Universität Halle, 1990. 
30 E. L. Gurevich and R. Hergenroder, J. Anal. At. Spectrom., 2007, 22, 1043-1050.

31 M. Burger, G. Schwarz, A. Gundlach-Graham, D. Kaser, B. Hattendorf and D. Gunther, J. Anal. At. Spectrom., 2017, 32, 1946-1959.

32 S. J. M. Van Malderen, J. T. van Elteren and F. Vanhaecke, J. Anal. At. Spectrom., 2015, 30, 119-125.

33 H. A. Wang, D. Grolimund, C. Giesen, C. N. Borca, J. R. ShawStewart, B. Bodenmiller and D. Gunther, Anal. Chem., 2013, 85, 10107-10116.

34 W. Muller, M. Shelley, P. Miller and S. Broude, J. Anal. At. Spectrom., 2009, 24, 209-214.

35 S. M. Eggins, L. P. J. Kinsley and J. M. G. Shelley, Appl. Surf. Sci., 1998, 127-129, 278-286.

36 I. Horn and D. Günther, Appl. Surf. Sci., 2003, 207, 144-157.

37 T. Luo, Z. Hu, W. Zhang, D. Günther, Y. Liu, K. Zong and S. Hu, J. Anal. At. Spectrom., 2018, 33, 1655-1663.

38 D. N. Douglas, A. J. Managh, H. J. Reid and B. L. Sharp, Anal. Chem., 2015, 87, 11285-11294.

39 M. Tanner and D. Günther, J. Anal. At. Spectrom., 2005, 20, 987-989.

40 T. Van Acker, S. J. M. Van Malderen, T. Van Helden, C. Stremtan, M. Šala, J. T. van Elteren and F. Vanhaecke, J. Anal. At. Spectrom., 2021, 36, 1201-1209.

41 S. Theiner, A. Schweikert, S. J. M. Van Malderen, A. Schoeberl, S. Neumayer, P. Jilma, A. Peyrl and G. Koellensperger, Anal. Chem., 2019, 91, 8207-8212.
42 T. Van Acker, S. J. M. Van Malderen, M. Van Heerden, J. E. McDuffie, F. Cuyckens and F. Vanhaecke, Anal. Chim. Acta, 2016, 945, 23-30.

43 K. P. Jochum, U. Weis, B. Stoll, D. Kuzmin, Q. Yang, I. Raczek, D. E. Jacob, A. Stracke, K. Birbaum, D. A. Frick, D. Günther and J. Enzweiler, Geostand. Geoanal. Res., 2011, 35, 397-429.

44 R. N. Straus, A. Carew, D. Sandkuijl, T. Closson, V. I. Baranov and A. Loboda, J. Anal. At. Spectrom., 2017, 32, 1044-1051.

45 RCoreTeam, R: A Language and Environment for Statistical Computing, $\mathrm{R}$ Foundation for Statistical Computing, Vienna, Austria, 2020.

46 RStudio Team, RStudio: Integrated Development for $R$, RStudio Inc., Boston, MA, 2019.

47 U. K. Maity, P. Manoravi, M. Joseph and N. Sivaraman, J. Anal. At. Spectrom., 2020, 35, 2840-2851.

48 O. Borovinskaya, M. Aghaei, L. Flamigni, B. Hattendorf, M. Tanner, A. Bogaerts and D. Günther, J. Anal. At. Spectrom., 2014, 29, 262-271.

49 S. J. M. Van Malderen, T. Van Acker and F. Vanhaecke, Anal. Chem., 2020, 92, 5756-5764.

50 D. A. Frick and D. Günther, J. Anal. At. Spectrom., 2012, 27, 1294-1303.

51 P. Becker, C. Neff, S. Hess, P. Weis and D. Günther, J. Anal. At. Spectrom., 2020, 35, 2248-2254. 